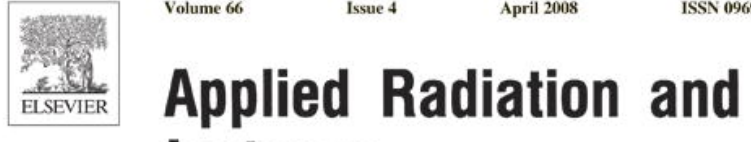 Isotopes \\ A journal of nuclear and radiation techniques and their applications in the physical, chemical, biological, medical, earth, planetary, environmental and engineering sciences
}

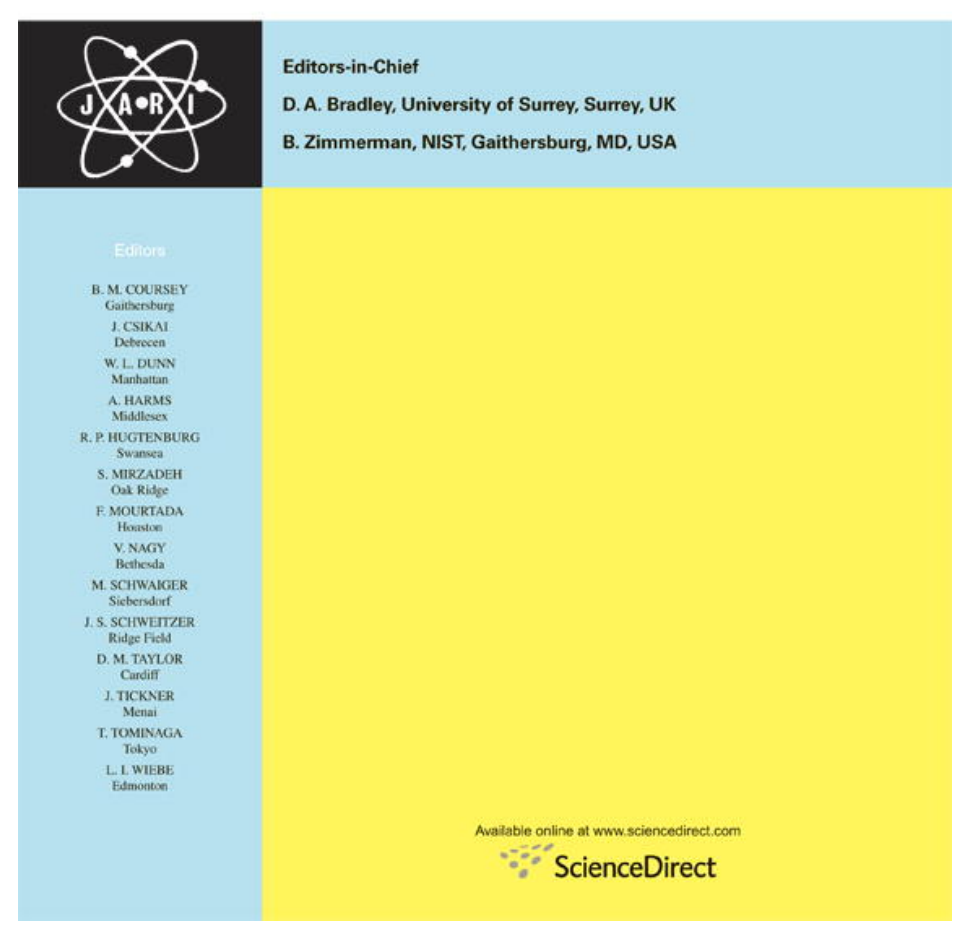

This article was published in an Elsevier journal. The attached copy

is furnished to the author for non-commercial research and education use, including for instruction at the author's institution, sharing with colleagues and providing to institution administration.

Other uses, including reproduction and distribution, or selling or licensing copies, or posting to personal, institutional or third party websites are prohibited.

In most cases authors are permitted to post their version of the article (e.g. in Word or Tex form) to their personal website or institutional repository. Authors requiring further information regarding Elsevier's archiving and manuscript policies are encouraged to visit: 


\title{
Evaluation of different counting methods for use in radiochemical purity testing procedures for ${ }^{99 \mathrm{~m}}$ Tc-labelled radiopharmaceuticals
}

\author{
Claudio Maioli ${ }^{\mathrm{a}, 1}$, Alberto Bestetti ${ }^{\mathrm{a}}$, Franco Milani ${ }^{\mathrm{a}}$, Gian Paolo Cornalba ${ }^{\mathrm{a}}$, Luca Tagliabue ${ }^{\mathrm{b}}$, \\ Domenica Di Benedetto $^{c}$, Ilaria Rognonic, Gian Luigi Tarolo ${ }^{\mathrm{a}}$, Rita Paronid,* \\ anstitute of Radiological Sciences, University of Milan, San Paolo Hospital, Milan, Italy \\ ${ }^{\mathrm{b}}$ Department of Nuclear Medicine, San Paolo Hospital, Milan, Italy \\ ${ }^{\mathrm{c}}$ Hospital Pharmacy San Paolo Hospital, Milan, Italy \\ ${ }^{\mathrm{d}}$ Department of Medicine, Surgery and Dentistry, University of Milan, San Paolo Hospital, via di Rudini' 8, 20142 Milan, Italy
}

Received 29 January 2007; received in revised form 10 July 2007; accepted 18 July 2007

\begin{abstract}
The efficiency and accuracy of different methods for quality control of radiopharmaceutical preparations for diagnostic purpose were studied. The radiochemical purity of ${ }^{99 \mathrm{~m}} \mathrm{Tc}$ Tetrafosmin, ${ }^{99 \mathrm{~m}} \mathrm{Tc}$ Exametazime, ${ }^{99 \mathrm{~m}} \mathrm{Tc}$ Sestamibi and ${ }^{99 \mathrm{~m}} \mathrm{Tc}$ Oxidronate was evaluated by different thin layer chromatography systems, followed by cutting of the strips into two or three sections and by the measurement of radioactivity distribution by dose calibrator or gamma counter. In addition, to confirm the accuracy of these routine procedures, the strips were cut into a number of micro-sections (14-25) and each of them evaluated by the gamma counter.

The three tested procedures gave similar results and revealed a good and comparable accuracy. The radioactivity measurement with the dose calibrator remains the most practicable because of the rapidity of execution.
\end{abstract}

(C) 2007 Elsevier Ltd. All rights reserved.

Keywords: Radiochemical purity; Radiopharmaceuticals; Quality control; ITLC-SG chromatography

\section{Introduction}

Use of radiopharmaceuticals in vivo needs radiochemical purity testing to be carried out just before administration to the patient. The methods used for quality control should not only be characterised by the highest accuracy and reliability, but should also be easy to perform and handle, safe and quick in order to ensure the use in a busy laboratory or in emergency situations (Dewanjee, 1990).

Exametazime $\quad[(R R, S S)$-4,8-diazo-3,6,6,9-tetramethylundecane-2,10-dione bisossime) (HM-PAO) is a highly lipophylic compound able to form a complex with ${ }^{99 \mathrm{~m}} \mathrm{Tc}$ and is mainly used for cerebral perfusion studies (Ballinger et al., 1988, 1990) or via administration of labelled

\footnotetext{
*Corresponding author. Tel.: + 390250323272 ; fax: + 390250323245 .

E-mail addresses: claudio.maioli@unimi.it (C. Maioli), rita.paroni@unimi.it (R. Paroni).

${ }^{1}$ Author for reprints request: Tel.: + 390250323055 ; fax: +390250323053 .
}

leukocytes for the diagnosis of inflammatory pathologies and infections (Bertrand-Caix et al., 1996). Exametazime may exist as the pharmacologically active isomeric forms $\mathrm{D}, \mathrm{L}$ and as the inactive meso form that must be removed from the precursor before use.

Mibi (2-methoxy-isobutyl-isonitrile)Cu(I) tetrafluoroborate) is a large synthetic molecule of the isonitrile family, which can be labelled with ${ }^{99 \mathrm{~m}} \mathrm{Tc}$ to form a complex with the Tc atom surrounded by six 2-methoxy-isobutylisonitrile $) \mathrm{Cu}(\mathrm{I})$ tetrafluoroborate groups $\left({ }^{99 \mathrm{~m}} \mathrm{Tc}\right.$ Sestamibi) (Hung et al., 1991). ${ }^{99 m}$ Tc Sestamibi was introduced in 1984 and has been used in clinical trials since the late 1980s (Munch et al., 1997; Taillefer, 1999; Lombardo et al., 2006). This molecule is a monovalent cation which passes cells membranes passively, the driving force being the negative membrane potential. Once intracellular it further accumulates in the mitochondrias where the membrane potential is even lower. ${ }^{99 \mathrm{~m}} \mathrm{Tc}$ Sestamibi is a radiopharmaceutical used for the study of myocardial perfusion. 
${ }^{99 m}$ Tc Tetrofosmin (1,2-bis[bis(2-ethoxyethyl) phosphino] ethane) (Myoview) is a cationic lipophylic cardiac imaging agent, useful in the diagnosis and localisation of regions of reversible myocardial ischaemia in the presence or absence of infarction under exercise and rest conditions (Munch et al., 1997; Nakajima et al., 1993). It is an alternative Tc-based synthetic imaging agent with properties, doses, administration protocols and diagnostic accuracy similar to Sestamibi (Lombardo et al., 2006). ${ }^{99 \mathrm{~m}} \mathrm{Tc}$ Sodium Oxidronate ( ${ }^{99 \mathrm{~m}}$ Tc HDP) is a radiopharmaceutical used for bone scintigraphy as it labels areas with impaired osteogenesis.

The aim of this paper was to evaluate in terms of efficiency, accuracy and rapidity, three different procedures to test the radiochemical purity of ${ }^{99 \mathrm{~m}} \mathrm{Tc}$ Tetrafosmin, ${ }^{99 \mathrm{~m}}$ Tc Exametazime, ${ }^{99 \mathrm{~m}}$ Tc Sestamibi, ${ }^{99 \mathrm{~m}}$ Tc Oxidronate, prepared just before the administration to the patients.

\section{Materials and methods}

The following drugs were used: ${ }^{99 \mathrm{~m}} \mathrm{Tc}$ Exametazime $\left({ }^{99 \mathrm{~m}}\right.$ Tc HM-PAO) [(RR,SS)-4,8-diazo-3,6,6,9-tetramethylundecane-2,10-dione bisossime)] (CERETEC V9A A01 ESAMETAZIMA, kit for the preparation of ${ }^{99 \mathrm{~m}} \mathrm{Tc}$ Exametazime, Amersham Plc., Buchs, UK), ${ }^{99 \mathrm{~m}}$ Tc Tetrafosmin (MYOVIEW, kit for the preparation of ${ }^{99 \mathrm{~m}} \mathrm{Tc}$ Tetrafosmin, Amersham plc), ${ }^{99 \mathrm{~m}}$ Tc Sestamibi (2-methoxyisobutyl-isonitrile) $\mathrm{Cu}(\mathrm{I})$ tetrafluoroborate) (Cardiolite, kit for preparation of ${ }^{99 \mathrm{~m}} \mathrm{Tc}$ Sestamibi, The Wellcome Foundation Ltd., London, UK), ${ }^{99 \mathrm{~m}} \mathrm{Tc}$ Oxidronate ( ${ }^{99 \mathrm{~m}}$ Tc hydroxymethylene diphosphonate) $\left({ }^{99 \mathrm{~m}} \mathrm{Tc}\right.$ HMDP) (OSTEOCIS $^{\circledR}$, kit for the preparation of ${ }^{99 m}$ Tc Oxidronate, CIS Bio International, Gif-Sur-Yvette CEDEX, France).

Lyophilised radiopharmaceuticals were reconstituted as suggested by manufacturers by qualified and expert technicians, following the requirements of radiological safety and under the supervision of a nuclear medicine physician. The drugs were reconstituted under stringent aseptic conditions.

\subsection{Protocol for radio-purity determination of ${ }^{99 m} \mathrm{Tc}$ Exametazime $\left({ }^{99 m}\right.$ Tc HM-PAO)}

The preparation for i.v. injection of Exametazime can be potentially contaminated by a secondary complex of ${ }^{99 \mathrm{~m}} \mathrm{Tc}$ Exametazime, by free pertechnetate, by hydrolyzed and reduced ${ }^{99 \mathrm{~m}} \mathrm{Tc}$. To fully define the chemical composition of the i.v. preparation two different chromatographic systems were used. About $3 \mu \mathrm{L}$ drop of the reconstituted drug was placed with a glass capillary at $2.5 \mathrm{~cm}$ from the bottom of two istant thin layer chromatography/silica gel (ITLC/SG) strips (Gelman, $2.5 \times 20 \mathrm{~cm}$ ) labelled with different colours. The strips were immediately placed in a TLC chamber containing either $1.5 \mathrm{~mL}$ of methylethylketone (system A), or sodium chloride $0.9 \%$ (system B) as mobile phase. After the solvent front reached the end-point $(\sim 15 \mathrm{~cm}$ from the bottom), the strips were removed, dried, cut at the middle $\left(R_{\mathrm{f}}=0.5\right)$ and the two sections (top and bottom) crushed within a $30 \mathrm{~mL}$ syringe, in order to make the geometry more homogeneous before radioactivity counting. In system A, the lipophylic complex ${ }^{99 \mathrm{~m}} \mathrm{Tc}$ Exametazime and the free pertechnetate migrates with $R_{\mathrm{f}}=0.8-1.0$, while the secondary complex of ${ }^{99 \mathrm{~m}}$ Tc Exametazime and the hydrolyzed and reduced ${ }^{99 \mathrm{~m}} \mathrm{Tc}$ do not move from the origin and could be calculated as

$A \%=\frac{A_{\mathrm{b}} \times 100}{A_{\mathrm{T}}}$,

$A_{\mathrm{T}}$ was the total TLC activity $=A_{\mathrm{t}}+A_{\mathrm{b}}$, where $A_{\mathrm{t}}$ is the activity of the upper part (top), $A_{\mathrm{b}}$ the activity of the lower part (bottom).

In system $\mathrm{B}$, only the pertechnetate migrates with $R_{\mathrm{f}}=0.8-1.0$, while the other three molecules remain at the origin. In the same way from system $B$, the $\%$ of free pertechnetate in the upper part of the strip could be calculated as $B \%=B_{\mathrm{t}} \times 100 / B_{\mathrm{T}}$. The radiochemical purity of the lipophylic complex ${ }^{99 \mathrm{~m}} \mathrm{Tc}$ Exametazime was calculated as $100-(A \%+B \%)$. This value must be above $80 \%$, proved that the drug is sampled and analysed within $30 \mathrm{~min}$ from the reconstitution.

\subsection{Protocol for radio-purity determination of ${ }^{99 m} T c$ Sestamibi}

A $3 \mu \mathrm{L}$ drop of ethanol was placed at $1 \mathrm{~cm}$ from the bottom of a pre-cut aluminium oxide TLC strip (Baker-Flex strip \# 1 B-F, $2.5 \times 7.5 \mathrm{~cm}$ ) with a glass capillary and immediately after, avoiding ethanol drying, a $3 \mu \mathrm{L}$ drop of ${ }^{99 \mathrm{~m}} \mathrm{Tc}$ Sestamibi was spotted on the top of ethanol spot and it was allowed to dry without heating ( $\sim 5 \mathrm{~min})$. The strip was then placed in a developing chamber (a $100 \mathrm{~mL}$ beaker, containing $5 \mathrm{~mL}$ of $95 \%$ ethanol, covered with Parafilm ${ }^{\circledR}$ for 10 min to equilibrate C system A) and left until the solvent front reached the $5 \mathrm{~cm}$ end-point The strip was then cut at $4 \mathrm{~cm}$ from the bottom and the two parts (top and bottom) treated as described above for radioactivity counting. The radiochemical purity of ${ }^{99 \mathrm{~m}} \mathrm{Tc}$ Sestamibi was calculated as $A_{\mathrm{t}} \times 100 / A_{\mathrm{T}}$. The drug purity must be $>90 \%$ otherwise the preparation will be discharged.

\subsection{Protocol for radio-purity determination of ${ }^{99 m} T c$ Tetrafosmin}

A Gelman ITLC/SG strip $(2 \times 20 \mathrm{~cm})$ was marked at $3 \mathrm{~cm}$ from the bottom (origin) and at $3 \mathrm{~cm}\left(R_{\mathrm{f}}=0.2\right), 12 \mathrm{~cm}$ $\left(R_{\mathrm{f}}=0.8\right)$ and $15 \mathrm{~cm}$ (solvent front) from the origin. A $10 \mu \mathrm{L}$ drop of the reconstituted drug was placed at the origin with a glass capillary and avoiding the spot to dry, the strip was put immediately into the developing chamber (a 100-mL glass cylinder covered with Parafilm ${ }^{\circledR}$ ) containing system $\mathrm{A}(10 \mathrm{~mL}$ of acetone:dichlorometane mixture, $35: 65$, v:v). When solvent front reached to the $15 \mathrm{~cm}$ mark 
(10 min), the strip was removed from chamber, allowed to dry and then cut at the three marks in three sections (bottom, medium and top). Each section were treated as above for radioactivity counting. The free pertechnetate migrates to the upper part of the strip; the ${ }^{99 \mathrm{~m}} \mathrm{Tc}$ Tetrafosmin migrates at the middle of the strip while the reduced ${ }^{99 \mathrm{~m}} \mathrm{Tc}$ Tetrafosmin and the hydrophilic impurities do not move from the origin. The radiochemical purity of ${ }^{99 \mathrm{~m}}$ Tc Tetrafosmin was calculated as $A_{\mathrm{m}} \times 100 / A_{\mathrm{T}}$, where $A_{\mathrm{m}}$ is the activity of the medium part. The radiochemical purity must be $>90 \%$, otherwise the drug preparation must be discharged.

\subsection{Protocol for radio-purity determination of ${ }^{99 m} T c$ oxidronate $\left({ }^{99 m}\right.$ Tc HMDP)}

A $10 \mu \mathrm{L}$ drop was placed with a syringe at $2.5 \mathrm{~cm}$ from the bottom of two ITLC-SG Gelman strips $(2.5 \times 20 \mathrm{~cm})$ and dried under flow of nitrogen. Strips were placed into two developing chambers containing system A $(\mathrm{NaCl}$ $0.9 \%, 5 \mathrm{~mL})$ and system B (1:1 methanol:acetone, v/v), respectively. After the solvent front reached the end point $(17 \mathrm{~cm}$ from the bottom), the strips were removed and allowed to dry. The strip A was cut at $R_{\mathrm{f}}=0.1$ and the strip B at $R_{\mathrm{f}}=0.9$. Each parts were treated as before for radioactivity counting. The $\%$ of hydrolyzed pertechnetate was calculated from strip A as: $A \%=A_{\mathrm{b}} \times 100 / A_{\mathrm{T}}$. The $\%$ of free pertechnetate was calculated from strip $\mathrm{B}$ as: $B \%=B_{\mathrm{t}} \times 100 / B_{\mathrm{T}}$. The $\%$ of ${ }^{99 \mathrm{~m}} \mathrm{Tc}$ bound to HMDP (radiochemical purity) was calculated as $100-(A \%+B \%)$. The radiochemical purity must be $>95 \%$.
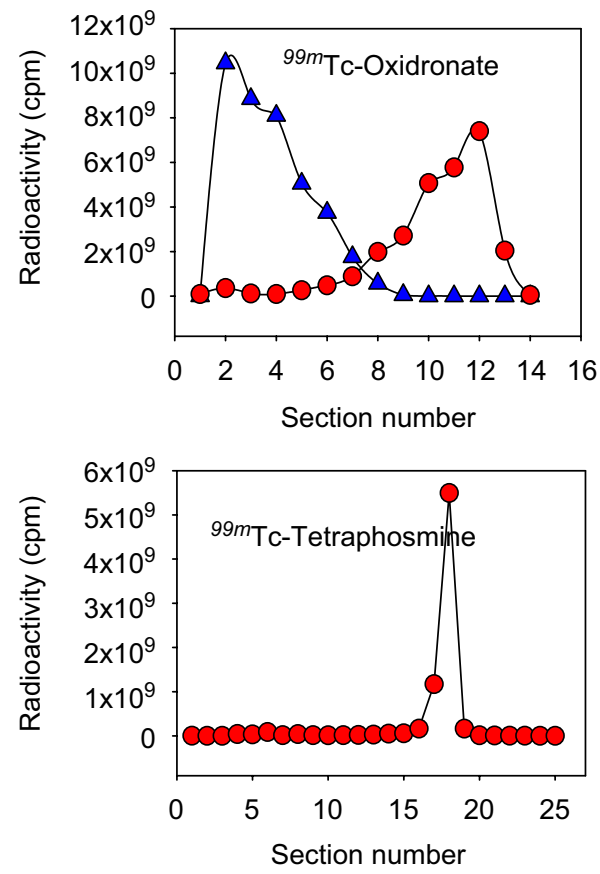

\subsection{Radioactivity counting}

The radiochemical purity was evaluated by measuring for $1 \mathrm{~min}$ the radioactivity of the different sections of the TLC strips with the Doses Calibrator (ISODOSE ACN, ACN, Italy), or with the gamma-counter COBRA II AutoGamma (Packard Bioscience Company, UK) set on the ${ }^{99 \mathrm{~m}} \mathrm{Tc}$ window. Due to the very high sensitivity of this instrument and to avoid saturation it was necessary to wait for $24 \mathrm{~h}$ before counting. As an alternative, to confirm the accuracy of above described routine procedures, the radioactivity distribution was evaluated by cutting the strips in 15-25 small sections (Fig. 1) and each of them evaluated by the gamma counter. The background was always subtracted from each measurement.

\section{Results and discussion}

The radiochemical purity $(\%)$ of the studied pharmaceuticals was not statistically different (Student $t$-test) when calculated with the three different measurement procedures (Table 1).

The dose calibrator is an instrument based on the use of a ionisation chamber for radioactivity counting, and is characterised by a background of $\sim 0.01-0.23 \mathrm{MBq}$. While the activity of the TLC sections containing the intact compound was always higher than fourfold the SD of the baseline noise, the radioactivity levels found in the strip pieces containing the contamination by-products, were closer to this background, suggesting a lower counting precision on these pieces and a possible overestimation of
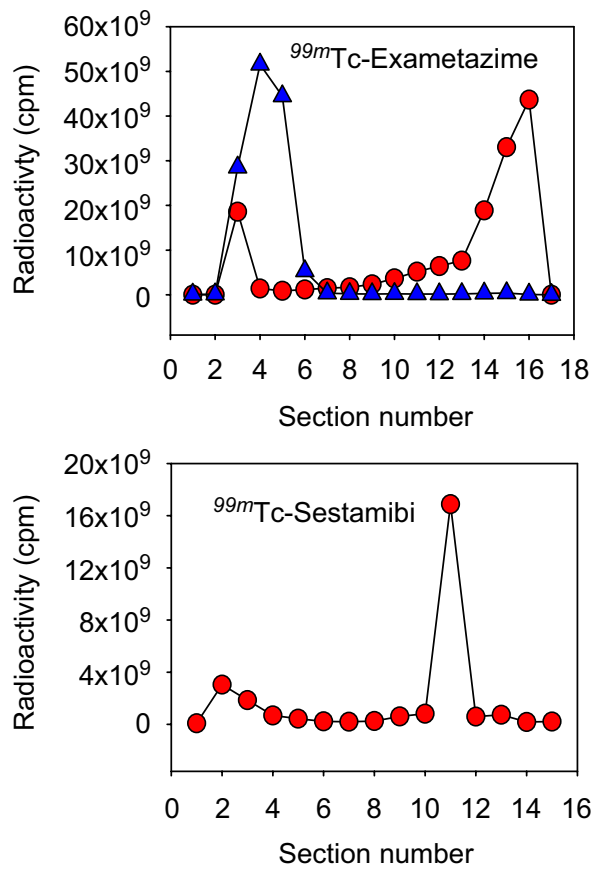

Fig. 1. Radioactivity distribution of ${ }^{99 \mathrm{~m}}$ Tc Oxidronate, ${ }^{99 \mathrm{~m}} \mathrm{Tc}$ Exametazime, ${ }^{99 \mathrm{~m}} \mathrm{Tc}$ Tetrafosmin, ${ }^{99 \mathrm{~m}}$ Tc Sestamibi evaluated by Gamma counter after cutting of TLC strips into many micro-sections. Chromatographic conditions for each drug are described in the text under Section 2 . The triangles in Oxidronate and Exametazime plots refer to radioactivity distribution in TLC system B. 
Table 1

Radiochemical purity of Tc drugs calculated with different testing methods

\begin{tabular}{|c|c|c|c|c|}
\hline \multirow[t]{2}{*}{ Drug } & \multicolumn{4}{|c|}{ Radiochemical purity (\%) } \\
\hline & Dose calibrator & Gamma counter & Radioactivity distribution & Reference values $^{\mathrm{a}}$ \\
\hline${ }^{99 \mathrm{~m}} \mathrm{Tc}$ Tetrofosmin & $97.9 \pm 1.0(n=15)$ & $96.6 \pm 0.5(n=10)$ & $97.9 \pm 0.5(n=3)$ & $>95$ \\
\hline${ }^{99 \mathrm{~m}}$ Tc Exametazime & $84.7 \pm 1.5(n=15)$ & $79.7 \pm 0.1(n=10)$ & $81.6 \pm 0.2(n=3)$ & $>80$ \\
\hline${ }^{99 m}$ Tc Sestamibi & $95.7 \pm 2.0(n=15)$ & $95.3 \pm 2.0(n=10)$ & $96.5 \pm 2.0(n=3)$ & $>90$ \\
\hline${ }^{99 \mathrm{~m}}$ Tc Oxidronate & $97.0 \pm 1.0(n=15)$ & $96.3 \pm 1.0(n=10)$ & $96.0 \pm 0.4(n=3)$ & $\geqslant 95$ \\
\hline
\end{tabular}

Results are reported as the mean \pm SD for the number of testing performed $(n)$.

${ }^{a}$ According to the Official Pharmacopoeia (FU) in Italy.

radiochemical purity with this method. However, this was not the case as quality control analysis performed with dose calibrator never revealed significant differences with results obtained with the gamma counter or with the radioactivity distribution analysis.

The COBRA II Auto-Gamma counter is an instrument characterised by high accuracy and precision (counting efficiency for ${ }^{99 \mathrm{~m}} \mathrm{Tc}=50 \%, \mathrm{CV}<0.1 \%$ ), thus the activity of the TLC sections containing the intact preparation $\left(>10^{6} \mathrm{cpm}\right)$ saturated the instrumental range and it was necessary to wait about 4 half-life of ${ }^{99 \mathrm{~m}}$ Tc (about $24 \mathrm{~h}$ ) before counting. This excluded its use in the clinical practice where the radiochemical purity must be assessed immediately after the drug preparation and before the administration to the patient.

In Fig. 1 is reported the radioactivity distribution obtained after cutting the TLC strips into slides and counting with the Gamma counter. The radioactivity purity in this case was calculated as sum of the activity of the different slides constituting the sections described under Section 2. The procedure for the evaluation of the radioactivity distribution was the more accurate one, with a performance comparable to the one obtained by using a chromatoscanner for the direct radioactivity distribution evaluation (data not shown), but is impaired by the long time needed for cutting the TLC strips into many different slices and by the lag-time of $24 \mathrm{~h}$ necessary before counting with the Gamma counter.

The three procedures used for the quality control evaluation of radiopharmaceuticals to be used for diagnostic purpose, indicated a radiochemical purity always higher than the reference allowed value for all the preparations and no significant differences were evidenced between results (mean \pm SD) obtained with the different radio-analytical methods. However, for ${ }^{99 \mathrm{~m}} \mathrm{Tc}$ HMPAO the method using the Gamma counter indicated a purity slightly lower than the target $(80 \%)$, thus resulting in a reject batch. This is probably attributable to the very high instability of the ${ }^{99 \mathrm{~m}}$ Tc HMPAO complex (manufacturers suggest the use within $30 \mathrm{~min}$ from the preparation) and to the long waiting period $(24 \mathrm{~h})$ necessary before radioactivity counting can be done by gamma counter.
In conclusion, the dose calibrator was the faster instrument (measure time $\sim 1 \mathrm{~min}$ ) and being present in all Nuclear Medicine departments, stands as the most convenient technique for the clinical use.

\section{Acknowledgements}

This work was in part supported by the Ministero Universita' e Ricerca Scientifica Tecnologica, Roma. The authors thank Mr. Michele Calabrese for his skilful technical assistance.

\section{References}

Ballinger, J.R., Reid, R.H., Gulenchyn, K.Y., 1988. Radiochemical purity of $\left[{ }^{99 \mathrm{~m}}\right.$ Tc]HM-PAO. J. Nucl. Med. 29 (4), 572-573.

Ballinger, J.R., Gulenchyn, K.Y., Reid, R.H., 1990. Radiopharmaceutical factors in the variable quality of $\left[{ }^{99 \mathrm{~m}} \mathrm{Tc}\right] \mathrm{HM}-\mathrm{PAO}$ images of the brain. J. Nucl. Med. 31 (1), 118-122.

Bertrand-Caix, J., Freyburger, G., Bordenave, L., Labrouche, S., Bareille, R., Baquey, C., et al., 1996. Functional upregulation of granulocytes labelled with technetium-99m-HMPAO and indium-111-oxinate. J. Nucl. Med. 37 (5), 863-868.

Dewanjee, M.K., 1990. The chemistry of ${ }^{99 \mathrm{~m}}$ Tc-labeled radiopharmaceuticals. Semin. Nucl. Med. 20 (1), 5-27.

Hung, J.C., Wilson, M.E., Brown, M.L., Gibbons, R.J., 1991. Rapid preparation and quality control method for technetium-99m-2methoxy isobutyl isonitrile (technetium-99m-sestamibi). J. Nucl. Med. 32 (11), 2162-2168.

Lombardo, A., Rizzello, V., Galiuto, L., Natale, L., Giordano, A., Rebuzzi, A., et al., 2006. Assessment of resting perfusion defects in patients with acute myocardial infarction: comparison of myocardial contrast echocardiography, combined first-pass/delayed contrastenhanced magnetic resonance imaging and ${ }^{99 \mathrm{~m}} \mathrm{TC}$-sestamibi SPECT. Int. J. Cardiovasc. Imaging 22 (3-4), 417-428.

Munch, G., Neverve, J., Matsunari, I., Schroter, G., Schwaiger, M., 1997. Myocardial technetium- ${ }^{99 m}$-tetrofosmin and technetium- $99 \mathrm{~m}$-sestamibi kinetics in normal subjects and patients with coronary artery disease. J. Nucl. Med. 38 (3), 428-432.

Nakajima, K., Taki, J., Shuke, N., Bunko, H., Takata, S., Hisada, K., 1993. Myocardial perfusion imaging and dynamic analysis with technetium-99m-tetrofosmin. J. Nucl. Med. 34 (9), 1478-1484.

Taillefer, R., 1999. The role of ${ }^{99 m}$-Tc sestamibi and other conventional radiopharmaceuticals in breast cancer diagnosis. Semin. Nucl. Med. 29 (1), 16-40. 